\title{
Um problema da administração municipal: das fontes textuais à cartografia de síntese (Lyon do século XVI ao XVIII)
}

\author{
[ For a problematization of municipal administration: textual sources \\ to the cartography of synthesis (Lyon I6th-I8th centuries)
}

\section{Olivier Zeller ${ }^{\mathrm{I}}$}

Texto traduzido do francês por Mônica Balestrin Nunes.

\begin{abstract}
RESUMO $\cdot O$ estudo de Lyon nos tempos modernos mostra que é impossível compreender a ação da administração municipal somente a partir das fontes escritas. Isso porque elas se referem geralmente a endereços difíceis de localizar com precisão, e porque parecem refletir apenas ações isoladas. Somente uma narrativa geral é possível trabalhando-se dessa maneira. A cartografia de precisão faz surgir as lógicas de funcionamento implícitas por trás das decisões aparentemente isoladas, localizando cada casa, associando-se casas e nomes, informando as transformações das ruas. Os agrupamentos de eventos espaciais sobre o mapa associaram as decisões antes impossíveis de visualizar: séries de reconstruções ao longo de novos alinhamentos, pavimentação de trechos de ruas, adução de água, localização da riqueza e pobreza, ligações políticas. Assim, as lógicas de planificação não mencionadas nas fontes escritas tornam-se evidentes. A geografia ajuda a fazer uma história que seja também uma história sobre o espaço e entrelaçada ao tecido urbano. P PALAVRASCHAVE - Geografia histórica; história urbana;
\end{abstract}

políticas de planejamento; tecido urbano; história social; Lyon. · ABSTRACT - The study of Lyons in modern times shows that it is impossible to understand the action of municipal authorities only from written sources. This is because they refer generally to places difficult to locate precisely, and because they seem to be only limited actions. Only a general narrative is possible working that way. The precise mapping makes appear the logics implicitly operating beyond apparently isolated decisions, locating every house, associating houses and names, informing the street transformations. The clusters of spatial events on the map show associated decisions otherwise impossible to see: series of re-buildings along new lines, paving of street sections, water conduits, location of wealth and poverty, political links. Thus, planning logics not mentioned in written sources become obvious. Geography helps making a history that be also a history in space and weaved with urban fabric. - KEYWORDS - Geographical history; urban history; planning politics; urban fabric; social history; Lyons.

Recebido em 5 de abril de 2016

Aprovado em 26 de julho de 2016

ZELLER, Olivier. Um problema da administração municipal: das fontes textuais à cartografia de síntese (Lyon do século XVI ao XVIII). Revista do Instituto de Estudos Brasileiros, Brasil, n. 64, p. 5I-64, ago. 2016.

DOI: http://dx.doi.org/Io.II606/issn.23I6-90IX.voi64p5I-64

I Université Lumière - Lyon 2 (Lyon, France). 


\section{INTRODUÇÃO: UM CAMPO DE PESQUISA ABANDONADO}

Os historiadores das municipalidades francesas do Antigo Regime escolheram limitar suas pesquisas a campos relativamente estreitos.

Anteriormente à ruptura epistemológica alcançada pela escola dos Anais, contentava-se com uma história de caráter puramente jurídico, geralmente marcada por uma nostalgia ingênua que gostava de retratar "patriciados" e "liberdades". A emergência de uma nova história social rompeu com essas formas convenientes, e a prosopografia ${ }^{2}$ dos grupos de poder constituiu a matéria de análises extremamente pertinentes, a exemplo do trabalho de Guy Saupin sobre Nantes3. À época, Jean-Claude Perrot havia proposto três campos de reflexão de grande riqueza potencial ${ }^{4}$. Como meio específico, como a cidade é o cadinho de comportamentos coletivos originais? Quais são os diferentes atores da governança urbana e como eles atuam no sentido da inércia ou da mudança? Não sendo o espaço urbano isomorfo, como se determinava e se perpetuava a geografia social? Tratava-se de lançar a problemática das permanências urbanas, um tempo animado pelo falecido Bernard Lepetit5. Mas o vento das modas virou muito rápido, e a importância que tomou a história cultural reduziu o interesse pelas municipalidades antigas à produção de mitos, graças à atividade historiográfica, ao exercício de ritos urbanos, notadamente festivos, e à sua indicação no espaço pela escrita ou pelos monumentos. Quanto ao retorno da história política, privilegiou-se o estudo das relações entre uma municipalidade e o

2 Prosopografia: descrição das feições do rosto, esboço de uma figura, conforme o Dicionário Aurélio.

3 SAUPIN, Guy. Nantes au XVIIe siècle. Vie politique et société urbaine. Rennes: Presses Universitaires de Rennes, I996.

4 PERROT, Jean-Claude. Genèse d'une ville moderne: Caen au XVIIIe siècle. Lille: Service de reproduction des thèses, I974 (rééd. Paris: Mouton, I975, 2 t.).

5 LEPETIT, Bernard. L'appropriation de l'espace urbain: la formation de la valeur dans la ville moderne (XVIe-XIXe). Histoire, économie et société, tome I3, n. 3, I994, p. 55I-559. 
poder central, o que reduziu seu alcance ao de uma monografia, exceto quando uma mudança de perspectiva permitia considerar a política real relativa às cidades, o que permitia se dedicar a um indispensável procedimento comparativo 6 .

Nesse contexto, desviou-se razoavelmente das práticas municipais de gestão do espaço urbano. A colocação de luminárias, o deslocamento de um bueiro, a realização de alguns trechos de pavimentação pareciam abandonados a uma erudição local um pouco folclórica. Entretanto, desde I983, Jean-Pierre Bardet mostrou, com o apoio de mapas, o quanto os níveis de equipamentos podiam variar de um bairro de Rouen a outro, e atribuiu ao estudo realidades materiais de uma dimensão social7.

\section{UM PROBLEMA DA ADMINISTRAÇÃo}

Resta, então, articular uma problemática especificamente voltada para a administração municipal. Ela se diferencia do urbanismo magistral que, respondendo antes de tudo a intuitos políticos, se interessava apenas pelas maiores cidades do reino e dependia mais dos grandes intendentes ou linhagens de governantes, e menos das municipalidades. Ela apresenta o interesse de ser aplicável na escala das pequenas ou médias cidades e, portanto, de se prestar a um procedimento comparativo. Trata-se de determinar as vontades tendo condicionado a organização do espaço urbano por práticas materiais corriqueiras. Em primeiro lugar, a rede viária, graças ao controle das construções ou reconstruções projetadas por particulares; a situação francesa não era uniforme, o poder pertencendo geralmente aos oficiais reais, os tesoureiros da França, localmente à municipalidade, como em Lyon, algumas vezes a diversas autoridades, como em Paris 8 . A autoridade tinha como interlocutores os particulares, mas também loteadores ou instituições eclesiásticas. O desafio era a melhoria da rede viária para liberação de cruzamentos e alargamento de ruas; mais raramente, compras de terras permitiam a criação de uma praça ou alguma intervenção eliminando antigos bloqueios. Um segundo desafio capital era o do tratamento das áreas públicas, seja a simples compactação do solo, seja a pavimentação com madeira ou pedra, e os pavimentos podiam ser naturais ou talhados. Diferentes sistemas eram aplicados, seja por financiamento, que podia ser tanto público, do orçamento municipal, quanto privado, a cargo dos moradores. A realização dos trabalhos podia ser entregue a artesãos calceteiros, a uma companhia escolhida ou a um serviço municipal. Não se tratava apenas de assegurar a "comodidade do tráfego". A cidade moderna era geralmente desprovida de qualquer sistema de esgotos. O sistema viário desempenhava, portanto, o papel de um sistema hidráulico encarregado de direcionar aos cursos d'água as águas pluviais e as águas servidas. Uma modificação pontual

6 FINLEY-CROSSWHITE, S. Annette. Henry IV and the towns. The pursuit of legitimacy in French urban society, I589-I6I0. Cambridge: Cambridge University Press, I999.

7 BARDET, Jean-Pierre. Rouen aux XVIIe et XVIIIe siècle. Les mutations d'un espace social. Paris: Sedes, I983, p. II3-II7.

8 PINON, Pierre. La Chaussée d'Antin à la fin du XVIIIe siècle. Bulletin de la Société de l'Histoire de Paris et de l'T̂le de France, II3e et II4e années, I986-I987, Paris, I988, p. 245. 
na declividade da rua não era uma obra sem importância. Segundo a regra da teoria dos miasmas, as estagnações eram bastante temerárias, o que conferiu à drenagem uma importante dimensão sanitária, o que valia também para o tratamento do lixo e dos "lodos", em grande parte de excrementos, que se espalhavam nas ruas. Por regulamentação ou por ação direta, as cidades asseguravam bem ou mal a limpeza das ruas, seja recorrendo aos camponeses que vinham recolher o adubo humano, seja financiando os carros municipais. Alguns intervinham de quando em quando, como Nervers, que mandava limpar os bairros mais pobres pelos camponeses do entorno quando o nível de sujeira tinha se tornado excessivo9. O perigoso, nauseabundo e custoso problema dos esgotos concentrava as preocupações: por muito tempo, os "mestres de trabalhos sujos" esvaziaram as fossas, mais tarde, no século XIX, as companhias especializadas propuseram seus serviços às municipalidades mais importantes.

A regulamentação municipal vinha como apoio a essa melhoria do viário. Sua eficácia variava consideravelmente em função do tamanho das cidades e dos meios financeiros e políticos dos quais podiam dispor as cidades. Por quase todos os lugares, os edis se confrontavam com os mesmos problemas: a melhoria do sistema viário herdado da Idade Média, a salubridade pública, o perigo de incêndio, a manutenção dos edifícios municipais, a pavimentação, ao menos localmente. Eles podiam se inspirar nos modelos que constituíam as grandes cidades. Desde I5II, os magistrados de Rodez se inspiravam explicitamente na regulamentação da construção aplicada em Lyon ${ }^{\text {Io }}$.

Evidentemente, os meios de ação municipais evoluíram consideravelmente no decorrer do Antigo Regime, do trabalho servil ao emprego de trabalhadores municipais e do recurso aos artesãos locais aos contratos com empresários de serviços públicos que, a partir do século XVIII, obtinham um decreto do Parlamento ou Cartas Patentes para explorar monopólios em diversas cidades, por exemplo: as de carros de praça, de adução de água, de fornecimento de luminárias, do esgotamento de fossas de vazão ou, relacionado aos seguros imobiliários, a dos serviços de limpeza ${ }^{\mathrm{II}}$.

A evolução dos modos de vida levou ao mesmo tempo ao uso do que se pode denominar um pouco anacronicamente de "mobiliário urbano". O século XVIII viu se multiplicarem as placas indicativas de rua, os bancos de pedra, as grades de proteção, as primeiras calçadas, ou ainda as luminárias, mesmo que em muitas cidades eles fossem adotados sob pressão, pois eram considerados inutilmente dispendiosos. O que era verdadeiro para as companhias de empreendedores o era também para os equipamentos e os especialistas: as cidades funcionavam em redes e, se os modelos de urbanismo ou de administração circulavam, o mesmo acontecia

9 GUENEAU, Louis. L'organisation du travail à Nevers aux XVIe et XVIIe siècles. Paris: Hachette, I9I9.

IO MOUYSSET, Sylvie. Le pouvoir dans la bonne ville. Les consuls de Rodez sous l'Ancien Régime. Rodez et Toulouse: Société des Lettres, Sciences et Arts de l’Aveyron et CNRS - Université de Toulouse Le Mirail, 2000.

II LIS, Catharina; SOLY, Hugo. Entrepreneurs, corporations et autorités publiques au Brabant et en Flandre à la fin de l’Ancien Régime. Revue du Nord, n. 76, I994, p. 725-744; ZELLER, Olivier. Une nouvelle gestion édilitaire au XVIIIe siècle : les entrepreneurs de services publics à Lyon. In: WORONOFF, Denis (Dir.). Mélanges offerts à Serge Chassagne. Valenciennes: Presses Universitaires de Valenciennes, 2008. 
com homens de saber reconhecido, por exemplo, os construtores de fontes ou de materiais especializados, como de extintores de incêndio, em geral de origem estrangeira. Havia até mesmo um mercado de mobiliário urbano usado. Por exemplo, quando as luminárias a vela das capitais provinciais se tornaram obsoletas pela introdução dos candeeiros a óleo, elas fizeram, com baixo custo, a felicidade dos edis das pequenas cidades ${ }^{\mathrm{I} 2}$.

\section{OS INSTRUMENTOS DE UMA MICROANÁLISE}

A cidade de Lyon foi escolhida como objeto de um primeiro estudo apoiado na problemática da administração municipal do século XVI ao século XVIII ${ }^{\mathrm{I}}$. Essa opção se justificava pela importância econômica e demográfica de uma cidade que passou em três séculos de 30 mil a quase I30 mil habitantes, da qual as construções e o sistema viário conheceram transformações extremamente marcantes e cujo urbanismo dependia, em grande parte, da autoridade municipal, pelo menos até I763.

Uma primeira fase da pesquisa, portanto, consistiu em vasculhar de maneira exaustiva as séries BB e DD dos Archives Municipales de Lyon, ou seja, o conjunto de registros de deliberações consulaires ${ }^{\mathrm{I} 4}$ e todas as coletâneas de atos atinentes ao urbanismo. Se, sob esta ótica, a série DD pode ser considerada como relativamente homogênea, não acontece o mesmo com os 287 registros da série $B B$, em que as decisões administrativas estão dispersas entre todos os atos da municipalidade. Foram necessários muitos anos para estabelecer séries de alinhamentos fixando, muito precisamente, as condições de construção ou de reconstrução de cada imóvel, assim como as indenizações dos proprietários, depois as permissões relativas às modificações de fachada, a fixação de anúncios, a colocação das pedras sobre o pavimento, as "cadettes", os trabalhos relativos aos poços fixos nas residências, a colocação de grades de proteção, assim como todos os procedimentos profissionais relativos ao espaço público, Foram também sistematicamente levantadas as diferentes injunções formuladas pela autoridade municipal, em particular os decretos de perigo ordenando a demolição de imóveis velhos e os processos verbais de infração às normas de construção. Em constante aperfeiçoamento, dispositivos regulamentadores condicionavam as formas de uso dos espaços públicos viários, e também portuários e fluviais. Os mesmos arquivos mostraram também numerosas ações de urbanismo empreendidas pelo Consulat a despeito da fragilidade dos recursos financeiros: pavimentação de determinadas ruas, criação de praças, realização de

I2 EL KORDI, Mohamed. Bayeux aux XVIIe et XVIIIe siècles. Contribution à l'histoire urbaine de la France. Paris - La Haye: Mouton, I970, p. 34; LAMARRE, Christine. Petites villes et fait urbain en France au XVIIIe siècle. Le cas bourguignon. Dijon : Editions Universitaires de Dijon, I993.

I3 Esse problema não afeta as grandes operações, geralmente impostas pela autoridade superior, que foram a construção do novo prédio da Prefeitura na metade do século XVII, a organização da praça Louis le Grand, a construção dos monumentais armazéns d'Abondance e do teatro, pelo arquiteto Soufflot no século XVIII

I4 Relativos à administração, conforme dicionário Petit Robert: Consul - magistrado municipal da região central da França. (NT.) 
equipamentos hidráulicos, organização de passeios, construção de edifícios públicos, organização material do serviço de incêndio. No século XVIII, os atos consulares mostram, por fim, a implantação de um novo mobiliário urbano. O conjunto pode ser completado pelas ordens de polícia e pelas notificações de infração reunidas na série FF, que, se peca por não ser exaustiva, não é menos rica em indicações muito preciosas para o conhecimento das práticas materiais.

Logo ficou evidente que, para ter sentido, o conjunto dessa massa documental deveria ser tratado num procedimento de cartografia sistemática. Ora, três dificuldades consideráveis tornavam extremamente difícil a localização dos objetos. A primeira residia no modo de identificação das construções e dos lugares. Os imóveis eram designados pelo nome de seu proprietário e, portanto, as denominações estavam sujeitas a alterações ao longo das mudanças de propriedade. Os atos mais ricos, notadamente os alinhamentos, dispunham de mais informações precisas mencionando os nomes dos vizinhos de três confrontações segundo os pontos cardeais, sendo a rua o quarto limite. A localização de cada imóvel se chocava então com quatro dificuldades maiores. A principal era o caráter circular das definições, os imóveis de um quarteirão se referenciando mutuamente, segundo seus vizinhos. A segunda dizia respeito à dificuldade de interpretação dos limites, dados sempre segundo os lados “de bise” "I (lado norte), "de vento" (lado sul), "da manhã" (lado leste) e "da tarde" (lado oeste), enquanto a trama viária não era ortogonal e não estava comumente orientada segundo os eixos norte-sul e leste-oeste. A terceira se referia ao caráter flutuante das denominações, que acarretava constantes perdas de referências no que concerne não apenas aos nomes das casas, mas também aos nomes das ruas, cujas denominações eram, salvo exceções indicadas, sujeitas aos usos populares correntes. Foi preciso, portanto, reconstituir as práticas em toda sua diversidade: uma mesma rua podia ter concorrentemente diversas denominações, e alguns deslizes hodonímicos ${ }^{\mathrm{I} 6}$ podiam se dar, como um nome passando algumas vezes de um segmento de via para outro dentro da mesma vizinhança. Somente a acumulação sistemática das indicações de denominação permitiu dissipar as aparentes contradições. Entretanto, a localização dos objetos de estudo estava longe de estar assegurada. A quarta dificuldade era a ausência de cadastro anterior ao início do século XIX, o que deixava na ignorância do loteador e, ipso facto, apenas permitia localizar cada imóvel vagamente, à margem de uma rua, entre dois cruzamentos.

A segunda fase da pesquisa consistiu então em reconstituir um cadastro evolutivo graças a um SIG (Sistema de Informações Geográficas). Só é possível aqui descrever em grandes linhas o método pacientemente elaborado por Bernard Gauthiez ${ }^{\mathrm{T}}$. O princípio norteador é o método regressivo, que se inicia pela análise do mais antigo registro gráfico abrangente, no caso o cadastro napoleônico, e depois o adapta, recuando no tempo, pela confrontação de suas indicações com a posição atual de

I5 Bise é um tipo de vento que sopra a partir do norte. MÉTÉOSUISSE - Office Fédéral de Météorologie et de Climatologie. Les différents noms de la bise. Disponível em: 〈http://www.meteosuisse.admin.ch/home/actualite/ meteosuisse-blog.subpage.html/fr/data/blogs/20I6/3/les-differents-noms-de-la-bise.html>. (N. T.)

I6 Hodonímia é a parte da toponímia que estuda os nomes das vias e praças. (N. T.)

I7 GAUTHIEZ, Bernard, em artigo apresentado neste volume. 
diversos imóveis antigos conservados, e pela restituição dos traçados viários tal como os planos mais antigos podiam descrevê-los. A fonte principal que permitiu relacionar a cada lote o nome de seu proprietário em determinada data foi a série dos alinhamentos: uma vez referenciado o imóvel, em particular no caso favorável em que ele estivesse situado numa esquina, a concatenação de dados permite, por aproximações sucessivas, demarcar sua posição em relação a cada residência formando uma sequência. $\mathrm{O}$ conhecimento do parcelamento foi em seguida refinado pela integração de documentos gráficos que representavam uma parte da cidade. Os mais detalhistas são os atlas terristas encontrados nos fundos senhoriais eclesiásticos, que compartilhavam as informações essenciais sobre o território urbano.

O alcance do método teria sido rapidamente limitado se não tivesse sido enriquecido por um novo tipo de aproximação. Tudo partiu de uma constatação: mesmo sendo totalmente desprovidas de qualquer indicação topográfica, as funções de fiscalização foram estabelecidas segundo uma lógica de itinerário, o que as norteou em seu estabelecimento inicial e foi respeitado depois, de cópia em cópia. Essa "espacialidade implícita" permitiu então traduzir uma ordem textual em ordem espacial, e, portanto, atenuar a insuficiência de fontes gráficas ${ }^{18}$. As bases de dados foram então direcionadas ao sequenciamento das propriedades de grandes fontes diacrônicas que são os documentos fiscais: imposto da vigésima ${ }^{\text {I9 }}$, taxas de iluminação, recenseamentos de I709, I636 e I597, imposto de empréstimos de I677, além das Nomeadas do século XVI, das quais os mais ricos descontam as lojas e os andares de cada imóvel. A dificuldade aqui é ter em conta as modificações realizadas no parcelamento, geralmente no sentido da fusão. Dificuldade, sobretudo, em reconstituir, elo, por elo, cada cadeia de propriedades de imóveis. Os arquivos do controle dos atos, que recapitulam, na França, todas as produções registradas a partir do fim do século XVII, começaram em Lyon apenas em I735. É preciso então mergulhar no oceano de minutas, de registros e de compatibilidade senhoriais para encontrar o traço textual das alterações mais antigas. Mas o SIG é suscetível de funcionar em sistema especializado desde que certa densidade de informações seja alcançada ${ }^{20}$. A partir do momento em que a localização de um imóvel é obtida em uma determinada data, a das edificações vizinhas é potencialmente possível. A cartografia evolutiva do parcelamento e da construção parece assim indefinidamente aperfeiçoável.

I8 GAUTHIEZ, Bernard; ZELLER, Olivier. Ordre textuel et ordre spatial à Lyon à l'époque moderne. Du parcours de visite au rôle nominal, une spatialité implicite. Histoire er mesure, v. XXV, n. 2, 2009.

I9 No original, "rôles de vingtièmes": imposto criado em I749, em substituição à décima (Dixième), estabelecia o valor de $20 \%$ da renda de todos, privilegiados ou não, segundo a declaração de cada um, sendo, porém, fiscalizado pelos controladores reais. Fonte: Transcription acte. Role imposition du vingtieme de SCAER de I787. Disponível em: 〈http://histoiresdeserieb.free.fr/releve_vingtieme.html〉. (N. T.)

20 GAUTHIEZ, Bernard, ZELLER, Olivier. Lyons, the spatial analysis of a city in the I7th and I8th centuries. Locating and Crossing Data in a GIS Built from Written Sources. In: RAU, Susanne; SCHOENHERR, Ekkehard (Ed.). Mapping spatial relations, their perceptions and dynamics - the city today and in the past. Heidelberg-New York-Dordrecht-Londres: Springer, 20I4, p. 97-II8. 


\section{Primeiros Resultados em 20I6 ${ }^{21}$}

Lançado em $2000^{22}$, o plano de pesquisa sobre a espacialidade lionesa permite hoje formular quatro grandes tipos de observações:

I) Longe de utilizar sistematicamente as divisões fundamentais em bairros, a cidade se dotou progressivamente de uma geografia administrativa diversificada em função dos objetivos.

2) A gestão do espaço urbano foi não somente levada a aperfeiçoar suas regras, mas a introduzir novas práticas, a exigir a observância de novas regras e a recorrer a novos tipos de financiamento.

3) A produção da cidade não fora gerada unilateralmente pela autoridade municipal. Ela se deu em interação constante com o investimento privado.

4) Aparentemente dispersas as diversas ações administrativas encontravam sua coerência realizando verdadeiros planos de locais de ordenação.

\section{A multiplicação das divisões administrativas}

A primeira observação coloca em evidência o uso de uma diversidade de divisões administrativas. Uma das principais definia os bairros da milícia, cuja finalidade não era exclusivamente militar, mas servir também de base para a organização festiva no século XVI e ao regramento de pequenos problemas de organização, formando um quadro permanente administrativo, fiscal, caritativo e policial. A malha passou por numerosas variações no decorrer dos três séculos de modernidade. Umas respondiam às necessidades de reajuste criadas pela evolução demográfica territorialmente diversificada. Outras serviam a uma geoestratégia de controle da população, modulando as divisões de maneira a definir os bairros ricos, que seriam mobilizados em caso de tumultos, e os bairros pobres, nos quais se evitaria armar os habitantes. Lyon foi assim dividida em 35, depois em 38 bairros no século XVI, número que caiu progressivamente a 35 no fim do século XVII, depois a 28 após a reforma que transformou a milícia popular em guarda burguesa após as revoltas de I744 e I745.

Mesmo que os oficiais dessas "pennonages"23 estivessem encarregados das questões policiais, tais como a luta contra a prostituição e a vigilância dos estrangeiros e vadios, a repressão cotidiana de pequenas infrações cabia aos "burgueses da polícia", cuja competência desenhava uma outra geografia. Nesse caso, também a realidade foi mutante. Nem as fronteiras dos bairros da milícia, nem aquelas dos bairros de polícia

\footnotetext{
2I Nota do editor: o desenvolvimento de tal metodologia e seus resultados são apresentados por Bernard Gauthiez no artigo precedente.

22 GAUTHIEZ, Bernard; ZELLER, Olivier. Lyon aux XVIIe-XVIIIe siècles, la fabrique de la ville. In: BAJOLET, Emilie; MATTEI, Marie-Flore; RENNES, Jean-Marc (Dir.). Quatre ans de recherche urbaine 200I-2004. ACI-Ville Ministère de la Recherche. Tours: Presses Universitaires François-Rabelais - Maison des Sciences de l'Homme "Villes et territoires", 2006, tome I, p. 459-464.
}

23 Cada um dos 36 bairros da cidade, ou "pennons". (N. T.) 
coincidiam com os limites paroquiais, herdados imutavelmente da Idade Média, e ultrapassando com frequência a linha das muralhas. Havia uma diferença notável em relação a outras cidades onde as paróquias serviam também como base fiscal, ou ainda daquelas onde os bairros formavam subdivisões do território paroquial.

Os progressos das práticas administrativas municipais levaram a imaginar outras divisões do território urbano. A gestão do entulho pretendia evitar que os pedreiros comprometessem o acesso aos portos fluviais jogando os restos de demolição nos cursos d'água tendo em vista que as operações de urbanismo necessitavam de seu reaproveitamento. Tratava-se, em particular, de nivelar a praça Bellecour e de diminuir o leito dos cursos d'água para criar as docas. A cidade foi então dividida em diferentes setores, sendo cada um responsável pelo despejo regular dos escombros das demolições realizadas em seu território. Assim, o regulamento de I645 dividiu a cidade em quatro zonas.

Outras divisões administrativas foram implementadas, por exemplo, para a coleta de resíduos nos porões e casas destruídas, ou ainda para fixar zonas de tarifas de serviços. O Consulat regulamentou assim o preço de transporte das mercadorias entre cada porto fluvial e seu bairro de chegada. No século XVIII, o preço do esvaziamento das fossas das latrinas foi também regulamentado, a companhia escolhida exigindo mais na cidade alta que na cidade baixa. Essa geografia desvantajosa para as zonas elevadas do Fourvière e da Croix-Rousse acontecia da mesma forma em matéria de iluminação. As luminárias só foram implantadas na parte mais densamente povoada e só foram instaladas na base dos morros ligando a cidade iluminada das zonas ribeirinhas à cidade escura das colinas; a cidade iluminada foi então dividia em sete setores especializados na patrulha da iluminação. Enfim, a organização do socorro contra incêndios terminou por criar sua própria geografia, desenhada sobre a trama dos limites de bairro e prevendo um sistema preestabelecido de apoio mútuo entre as unidades de vizinhança.

\section{A diversidade dos objetivos e dos métodos da gestão espacial}

Fixando o objetivo de assegurar uma largura mínima de ruas - treze pés no caso de Lyon -, a municipalidade definiu uma política de alinhamentos a longo prazo. Um planejamento verdadeiramente abrangente foi imposto pelo tenente-general em I680. As regras impostas às questões construtivas podiam proibir alguns materiais e, sobretudo, banir tudo o que pudesse obstruir a via pública, como toldos, bancas, galerias, anúncios ou calhas de água pluvial. Impondo o arredondamento na parte baixa dos imóveis, os “cantos", elas obedeciam, também, ao princípio do tráfego, alargando os cruzamentos para permitir às charretes e carroças virarem mais facilmente. A regulamentação urbana se aplicava enfim às formas de uso da via pública, depois à estocagem de madeira e, principalmente, de lenha de aquecimento, à utilização do espaço fluvial, tanto dos portos, onde diferentes atividades se instalavam em zonas especificas, quanto ao longo das margens, onde, num contexto de extrema penúria de espaço, uma verdadeira patrulha fluvial definia o local de instalação de cada moinho, de cada estabelecimento de banhos, de cada "usina" que utilizava a força motriz do rio, de cada "bachat”, um tipo de barco específico 
que permite a conservação do peixe vivo, ou de cada "platte", barco destinado às lavadeiras. Rapidamente, os imperativos do tráfego incitaram a municipalidade a instaurar regras de circulação e de estacionamento, organizando o acesso das charretes nas bordas das zonas portuárias e a parada das carroças nas proximidades do teatro ou limitando a amarração das embarcações ao tempo de sua descarga. A mesma preocupação motivou as aberturas ou alargamentos das ruas e das docas: na margem direita do Saône, tratava-se de resolver a estreiteza do caminho norte-sul com a abertura de um segundo itinerário; entre o Rhône e o Saône, o alargamento das docas respondia ao mesmo problema, de facilitar a circulação contornando os bairros centrais pelo oeste e pelo leste.

Ao mesmo tempo, a administração se preocupava em equipar a cidade. Por muito tempo considerados privados e, como tais, financiados, os poços acabaram se beneficiando dos financiamentos públicos, assim como, evidentemente, as fontes, que necessitavam da realização de obras de captação, de condução e excepcionalmente de distribuição. A atenção dispensada ao tráfego levava a multiplicar os "portos" (acesso às margens dos cursos d'água) para assegurar sua divisão entre diferentes usos, com frequência conflituosos, que eram o transporte, os bebedouros de animais, o despejo dos tonéis de dejetos e o acesso à água destinada ao uso doméstico. Era importante também financiar uma manutenção constante, uma vez que esses equipamentos sofriam muito com as grandes cheias, mas também com a deterioração causada pelos usuários. Atenuar o congestionamento crônico da ponte do Saône supunha a multiplicação das pontes de passagem. $\mathrm{O}$ estado das finanças municipais permitia apenas construir pontes de madeira para pedestres: no século XVII, as duas primeiras foram construídas pela companhia parisiense de Christophe Marie em Saint-Vincent e em Bellecour; no século seguinte, o desejo de obter recursos para os hospitais assegurou o retorno das balsas laçadas sobre o Rhône e das pontes de Serin e de Ainay sobre o Saône.

A administração lionesa se preocupou igualmente em construir edifícios de utilidade pública. A cidade construiu, no século XVI, um de seus dois grandes abatedouros, o de Terreaux, sendo o outro de propriedade do Hotel Dieu, que causava prejuízos. Ela construiu, também em I670, um mercado coberto para peixes, difícil de arrendar em razão da persistência da venda imediata. Para afastar o perigo de incêndio e dispersar o mau cheiro, criou fundições municipais com arquitetura concebida para garantir uma boa segurança. Sempre para evitar incômodos, ela mantinha a feira à beira d’água. A política adotada tendia a limitar o máximo possível a importância do patrimônio fundiário municipal, que se completava apenas com alguns escritórios de cobrança e alguns quartéis junto aos portões. O Consulat abandonou assim à iniciativa privada a construção do Loge des Changes e da Sala de Concerto, ambos tendo se tornado desastres financeiros. 


\section{A interação com o investimento privado}

O cruzamento das indicações topográficas do SIG e de diferentes fontes quantitativas permitiu atribuir um valor fundiário datado para a quase totalidade dos imóveis ${ }^{24}$. A evolução do preço da construção levantado para um mesmo lote pode ser determinada diretamente graças aos atos notariais e à avaliação feita em I698 para definir a taxa das luminárias. Foi também possível calcular indiretamente a partir do imposto da Vigésima, imposto que representava, como seu nome indica, $5 \%$ do valor locativo. Sabendo que os rendimentos fundiários variavam, conforme o bairro, de $3,5 \%$ a $5 \%$, bastou aplicar um multiplicador adaptado para avaliar cada imóvel. A cartografia dos valores fundiários assim obtida permitiu refinar uma análise espacial que a concepção das fontes havia por muito tempo limitado a uma comparação global por bairro25. Ela relativiza o significado dos valores médios e esclarece a variabilidade de valores de um segmento de uma mesma rua a outra ou, mais genericamente, segundo essa hierarquia viária pronunciada que apenas as microanálises urbanas sabem colocar em evidência ${ }^{26}$. In fine, aparece fortemente a interação entre a ação municipal e o investimento privado: com frequência uma melhoria viária era seguida de uma fase de reconstrução, aumentando o valor dos imóveis. O motor da mudança era, nesse caso, o alinhamento, ou melhor, suas consequências arquitetônicas. Fosse numa fachada declarada em "perigo iminente" e cuja demolição foi ordenada pelo Consulat, fosse um proprietário que pedia autorização para reformar sua casa. Em ambos os casos, um recuo podia ser exigido, o que era de lei, se não excedesse um pé e meio, e indenizável quando fosse maior ${ }^{27}$. Os imóveis lioneses possuíam fachadas estreitas, e os pavimentos eram levantados sistematicamente por paredes de meação. A destruição de um deles desestabilizava seus vizinhos. Era proibido reparar as paredes assim construídas. Pouco a pouco, como num efeito dominó, o recuo de um imóvel levava consigo os recuos dos demais imóveis daquele trecho de rua. Mas a dinâmica da renovação não parava aí. Ocorreu que os proprietários de ruas adjacentes começaram a renovar seus imóveis, originando uma onda de reconstrução que atingiu, em alguns anos, a quase totalidade dos imóveis na zona mencionada.

24 Nota do editor: observar, no texto de Bernard Gauthiez, os mapas da evolução dos valores fundiários dos imóveis (figuras 7 a Io).

25 ZELLER, Olivier. Les recensements Lyonnais de I597 et de I636. Démographie historique et géographie sociale. Lyon: Presses Universitaires de Lyon, I983; CABANTOUS, Alain. Le quartier, espace vécu à l'époque moderne: ambiguïté et perspectives d'une histoire. Histoire, économie et société, v. I3, n. 3, I994, p. 427-439.

26 JUNOT, Yves. Mixité sociale, habitat et propriété: la paroisse Saint-Jacques de Valenciennes en I602 d'après un registre du Iooe. Revue du Nord, n. 79, I997, p. 4I3-427.

27 GAUTHIEZ, Bernard; ZELLER, Olivier. Le dédommagement des reculements: un instrument de la politique d'aménagement urbain à Lyon aux XVIIe et XVIIIe siècles. Histoire er mesure, 20I3, v. XXVIII. 


\section{A coerência da organização na escala local}

Diversas realizações que poderiam ter passado como isoladas, tais como uma pavimentação, uma melhoria hidráulica, inscrições, prescrições arquitetônicas, encontravam coerência no que a cartografia de síntese mostra como sendo, de fato, uma operação local de organização urbana. O conhecimento dos valores fundiários permite então demonstrar que a municipalidade operava com cartas marcadas, com primazia de certos equipamentos destinados a bairros da elite ${ }^{28}$. Por exemplo, havia por volta de I760 uma convergência evidente entre a criação do novo bairro Saint-Clair, grande, burguês e nobre, a construção da quase totalidade dos imóveis do bairro do Plâtre, a escolha da localização do novo teatro, a melhoria do cais de Retz, a colocação dos primeiros passeios, as regras de estacionamento impostas aos carros e a grande densidade de cafés. Da mesma forma, o outro lugar de passeio que se constituía na praça Louis-le-Grand justificava a ampliação dos trabalhos hidráulicos, a manutenção dos gramados, das árvores e dos lagos por trabalhadores especializados, a colocação de bancos e de pequenas barreias de madeira, e até mesmo o emprego de um carrinho regador para combater a poeira dos caminhos.

\section{ConClusão}

O exemplo de Lyon mostrou que seria quase impossível escrever a história da administração municipal a partir de fontes puramente textuais. Isso por duas razões: elas se referem a lugares dificilmente identificáveis e, amplamente disseminadas ao longo do tempo, parecem, à primeira vista, não ter outro alcance que não o puramente pontual. Elas só permitem, portanto, construir um discurso geral, superficial.

Apenas a cartografia sistemática permite superar isso. Referenciando cada casa ou cada lote e desenhando o traçado evolutivo das ruas e praças, ela permite passar a uma escala de observação mais refinada, e então romper as imprecisões das abordagens tradicionais. Sobretudo, permite apenas evidenciar a lógica tendo tacitamente orientado o ordenamento de subespaços urbanos. Reunindo graficamente trabalhos aparentemente independentes, como o alinhamento, a pavimentação e a hidráulica, coloca em evidência sua complementaridade real. Tornando a colocar essas ações administrativas no contexto da geografia das riquezas que traduzem os valores fundiários, ela dá sentido também ao campo social.

Assim, a cartografia, à escala mais precisa possível, pode desempenhar um duplo papel: o de instrumento de pesquisa, no sentido experimental do termo da conciliação espacial e/ou cronológica de ações sem ligação aparente podem visualmente surgir, ou não, observações cuja coerência é de ordem territorial; o da ilustração, no melhor sentido do termo - diacrônico ou sincrônico conforme o caso,

28 GAUTHIEZ, Bernard, ZELLER, Olivier. Espace construit, espace social à Lyon aux XVIIe-XIXe siècle: l'apport du SIG. In: PANZERI, Matteo; FARRUGIA, Angela (a cura di). Fonti, metafonti e GIS per l'indagine della struttura del território. Torino, Celid/Politecnico di Torino, 2009, p. 39-50, p. II4-II7. 
um mapa deve ter valor de prova da validade de análises propostas. A geografia serve aqui à elaboração de uma história que permanece uma história do terreno.

\section{SOBRE O AUTOR}

OLIVIER ZELLER é professor emérito da Université Lumière Lyon 2, Lyon, France e pesquisador do Centre National de la Recherche Scientifique, UMR 5600 Environnement, Ville, Société.

\section{REFERÊNCIAS BIBLIOGRÁFICAS}

BARDET, Jean-Pierre. Rouen aux XVIIe et XVIIIe siècle. Les mutations d'un espace social. Paris: Sedes, I983, p. II3-II7.

CABANTOUS, Alain. Le quartier, espace vécu à l'époque moderne: ambiguïté et perspectives d'une histoire. Histoire, économie et société, v. I3, n. 3, I994, p. 427-439.

EL KORDI, Mohamed. Bayeux aux XVIIe et XVIIIe siècles. Contribution à l'histoire urbaine de la France. Paris - La Haye: Mouton, I970.

FINLEY-CROSSWHITE, S. Annette. Henry IV and the towns. The pursuit oflegitimacy in French urban society, I589-I6IO. Cambridge: Cambridge University Press, I999.

GAUTHIEZ, Bernard; ZELLER, Olivier. Espace construit, espace social à Lyon aux XVIIe-XIXe siècle: l'apport du S.I.G. In: PANZERI, Matteo; FARRUGIA, Angela (a cura di). Fonti, metafonti e GIS per l'indagine della struttura del território. Torino, Celid/Politecnico di Torino, 2009, p. 39-50, p. II4-II7.

; ___ . Lyon aux XVIIe-XVIIIe siècles, la fabrique de la ville. In: BAJOLET, Emilie; MATTEI, MarieFlore; RENNES, Jean-Marc (Dir.). Quatre ans de recherche urbaine 200I-2004. ACI-Ville Ministère de la recherche. Tours : Presses Universitaires François-Rabelais - Maison des Sciences de l'Homme "Villes et territoires", 2006, tome I, p. 459-464.

. Ordre textuel et ordre spatial à Lyon à l'époque moderne. Du parcours de visite au rôle nominal, une spatialité implicite. Histoire er mesure, v. XXV, n. 2, 2009.

;___. Le dédommagement des reculements: un instrument de la politique d'aménagement urbain à Lyon aux XVIIe et XVIIIe siècles. Histoire er mesure, 20I3, v. XXVIII.

;___ Lyons, the spatial analysis of a city in the I7th and I8th centuries. Locating and Crossing Data in a GIS Built from Written Sources. In: RAU, Susanne; SCHOENHERR, Ekkehard. Mapping spatial relations, their perceptions and dynamics. the city today and in the past. Heidelberg-New YorkDordrecht-Londres: Springer, 2014, pp. 97 -II8.

GUENEAU, Louis. L'organisation du travail à Nevers aux XVIe et XVIIe siècles. Paris: Hachette, I9I9.

JUNOT, Yves. Mixité sociale, habitat et propriété: la paroisse Saint-Jacques de Valenciennes en I602 d'après un registre du Iooe. Revue du Nord, n. 79, I997, p. 4I3-427.

LAMARRE, Christine. Petites villes et fait urbain en France au XVIIIe siècle. Le cas bourguignon. Dijon: Editions Universitaires de Dijon, I993

LEPETIT, Bernard. L'appropriation de l'espace urbain: la formation de la valeur dans la ville moderne (XVIe-XIXe). Histoire, économie et société, tome I3, n. 3, I994, p. 55I-559.

LIS, Catharina; SOLY, Hugo. Entrepreneurs, corporations et autorités publiques au Brabant et en Flandre à la fin de l'Ancien Régime. Revue du Nord, n. 76, I994, p. 725-744. 
MOUYSSET, Sylvie. Le pouvoir dans la bonne ville. Les consuls de Rodez sous l'Ancien Régime. Rodez et Toulouse: Société des Lettres, Sciences et Arts de l'Aveyron et CNRS - Université de Toulouse Le Mirail, 2000.

PERROT, Jean-Claude. Genèse d'une ville moderne: Caen au XVIIIe siècle. Lille: Service de reproduction des thèses, I974 (rééd. Paris: Mouton, I975, 2 t.).

PINON, Pierre. La Chaussée d'Antin à la fin du XVIIIe siècle. Bulletin de la Société de l'Histoire de Paris et

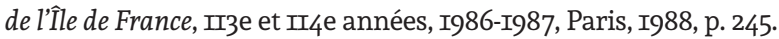

SAUPIN, Guy. Nantes au XVIIe siècle. Vie politique et société urbaine. Rennes: Presses universitaires de Rennes, I996.

ZELLER, Olivier. Les recensements Lyonnais de I597 et de I636. Démographie historique et géographie sociale. Lyon: Presses universitaires de Lyon, I983.

Une nouvelle gestion édilitaire au XVIIle siècle: les entrepreneurs de services publics à Lyon. In: WORONOFF, Denis (Dir.). Mélanges offerts à Serge Chassagne. Valenciennes: Presses Universitaires de Valenciennes, 2008. 